\title{
O ne-tube Nested Polymerase Chain Reaction for Detection of Chlamydia trachomatis
}

\author{
Pamela Cribb, Juan Pablo Scapini* , Esteban Serra/ ${ }^{+}$
}

Instituto de Biología Molecular y Celular de Rosario, Facultad de Ciencias Bioquímicas y Farmacéuticas, Suipacha 531, 2000

Rosario, Argentina *Instituto de Investigaciones Microbiológicas y Clínicas, 2000 Rosario, Argentina

Here we present a one-tube nested PCR test, which allows the detection of minimal quantities of Chlamydia trachomatis in human fluids. This assay includes the use of an internal control to avoid false negative results due to the presence of inhibitors. The results obtained show that this assay is robust enough to be used for clinical diagnosis.

Key words: Chlamydia - Polymerase Chain Reaction - diagnostic

Chlamydia trachomatis infections are the most prevalent bacterial sexually transmitted diseases worldwide (Gerbase et al. 1998). Most chlamydial infections are asymptomatic both in men and women. However, if not treated properly they can lead to severe sequelae in women, such as pelvic inflammatory disease, ectopic pregnancy, and tubal infertility (Marrazzo \& Stamm 1998). Taking into account that chlamydiae are sensitive to antibiotics, it is crucial to have an accurate method for the diagnosis of infections.

Most amplification methods developed to detect $C$. trachomatis in urethral, cervical and urine specimens, have demonstrated to be more sensitive than cell culture or antigen detection methods (Black 1997). There are commercial methods currently available, such as AMPLICOR CT PCR, of Roche Molecular Systems which detects the amplification products using hybridization to an avidinhorseradish peroxidase (HRP) conjugate, or Digene signal amplification-based Hybrid Capture (HC) II CT-ID test system. Commercial methods have important advantages, but their cost make them unavailable for many laboratories. Several non-commercial amplification methods have been also described. Most of them consist of a single PCR whose products are analyzed by gel-based methods. Agarose gel electrophoresis with ethidium bromide staining is a simple and inexpensive detection method commonly used, but lacks on sensitivity due to the presence of inhibitors in clinical samples. Even in the absence of PCR inhibitors, a single PCR followed by ethidium bromide-stained gel electrophoresis may not be sensitive enough to detect DNA from a sample containing only a

This work was supported by Fundación Antorchas and Third World Academy of Sciences.

${ }^{+}$Corresponding author. Fax: +54-341-439.0465. E-mail: eserra@arnet.com.ar

Received 12 December 2001

Accepted 17 April 2002 few elementary bodies (EB) of $C$. trachomatis. According to the formula proposed by Saiki et al. (1985), the number of copies " $\mathrm{P}$ " of the amplified sequence after " $\mathrm{n}$ " cycles of PCR is $\mathrm{P}_{\mathrm{n}}=\mathrm{P}_{\mathrm{o}}(1+E)^{\mathrm{n}}$, where $\mathrm{P}_{\mathrm{o}}$ is the initial number of copies of the target sequence, and $E$ is the efficiency of amplification $(0 \leq E \leq 1)$. Assuming that approximately 25 ng of DNA are detectable in an ethidium bromide stained gel, which represents $10^{11}$ copies of a $200 \mathrm{pb}$ fragment; theoretical calculations demonstrate that, starting with 10 initial molecules of template, the global efficiency of the reaction after 35 cycles needs to be higher than 0.9 to generate a detectable product. Although this efficiency can be achieved in a research laboratory, it is not routinely accomplished in a clinical diagnostic laboratory, rendering the assay not suitable to be used with clinical samples (Schmidt 1997). In order to have a sensitive assay for the detection of $C$. trachomatis to be routinely used in our laboratory, we designed a nested PCR based on the assay previously described by Mahony et al. (1992). Nested PCR uses two pairs of oligonucleotides (KL5/KL6 and KL1/KL2) complementary to sequences of the $C$. trachomatis cryptic plasmid, and following two rounds of amplification generates a $241 \mathrm{bp}$ final product (Fig. 1A). Originally, the first reaction was prepared in a final volume of $50 \mu \mathrm{l}$ containing $10 \mathrm{mM}$ Tris ( $\mathrm{pH}$ 9.0), 50 $\mathrm{mM} \mathrm{KCl}, 3.5 \mathrm{mM} \mathrm{MgCl}_{2}, 5 \mathrm{nmol}$ each dNTP, 20 pmol each outer primer KL5 (5'-TTTGCCTTAACCCCACCATT-3') and KL6 (5'-CGTCCTTCCTAAAAGAGCTA-3') and 1.25 U Taq polymerase (Promega). After 35 cycles consisting of $1 \mathrm{~min}$ at $94^{\circ} \mathrm{C}, 1 \mathrm{~min}$ at $55^{\circ} \mathrm{C}$, and $1 \mathrm{~min}$ at $72^{\circ} \mathrm{C}$ and a final elongation step of $7 \mathrm{~min}$ at $72^{\circ} \mathrm{C} ; 1 \mu \mathrm{l}$ of the first PCR product was transferred to a second reaction tube with the same composition except for the primers. In this case, 20 pmol of inner primers KL1 (5'-TCCGGAGCGAGTTAC TAAGA-3') and KL2 (5'-AATCAATGCCCGGGATTGGT3 ) were added to the reaction mix, and 35 new cycles were performed. The products were analyzed by agarose gel electophoresis stained with ethidium bromide.

As mentioned above, a critical problem for PCR-based diagnostic methods is the presence of inhibitors of the reaction in clinical samples which may lead to false nega- 

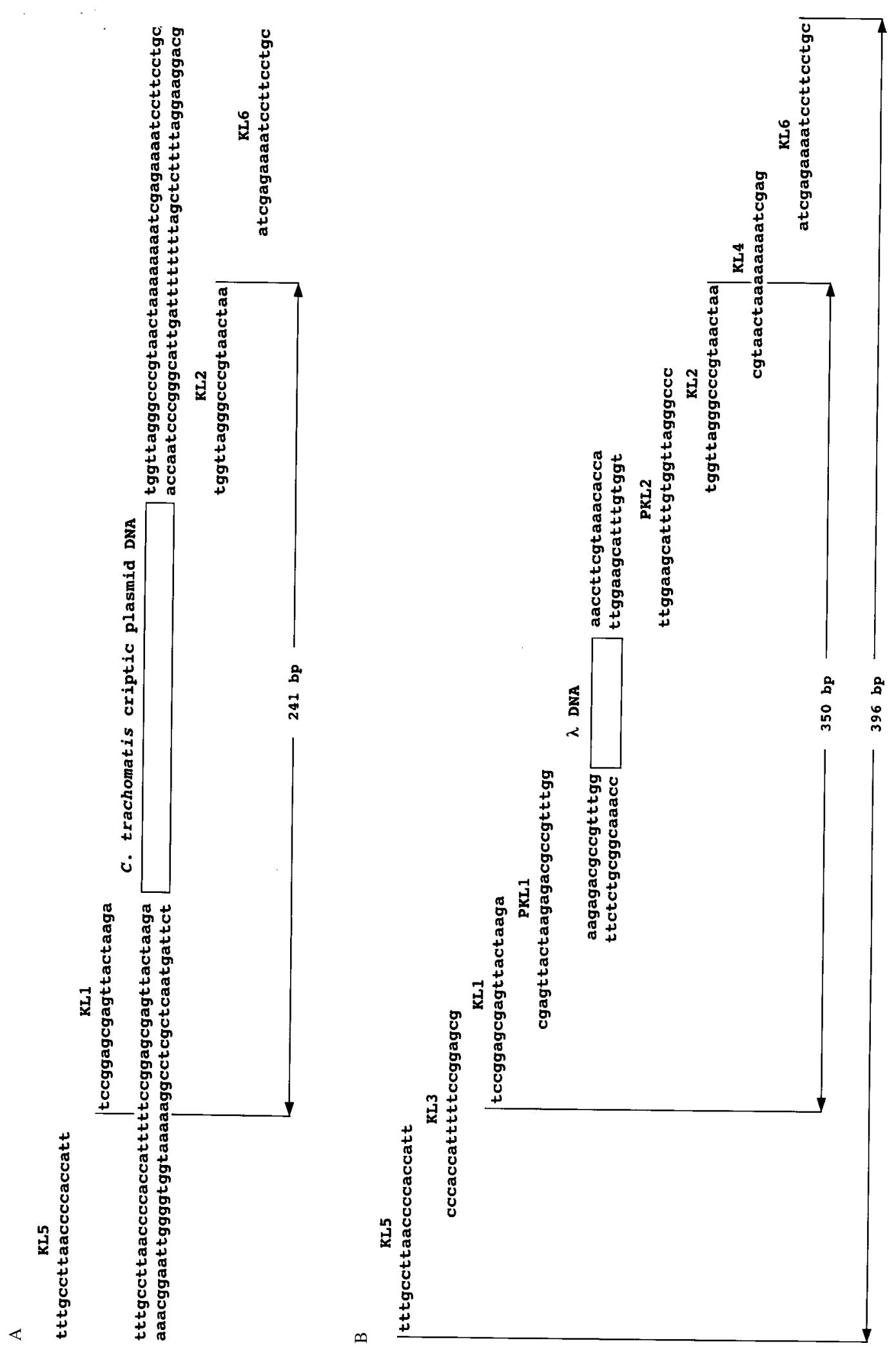

Fig. 1: schematic localization of primers used. A: chlamydial specific primers used in the nested PCR. KL5 and KL6 were used in the first reaction and KL1 and KL2 in the second. After the 2nd round of PCR, samples containing chlamydial DNA generate an amplification product of $241 \mathrm{bp}$; B: primers used in the construction of the hybrid internal control. Four PCRs with primers PKL1/PKL2, KL1/KL2, KL3/KL4 and KL5/KL6 were performed sequencially to obtain a 396 bp hybrid DNA fragment, which was cloned in the pGEM-T vector rendering the control plasmid pPC396. KL5/KL6 and KL1/KL2 are the same primers used in the nested PCR, whereas KL3/KL4 and PKL1/PKL2 are hybrid primers used only in the hybrid internal control construction. pPC396 generates a nested PCR final product of 350 bp, which can be easily distinguished from the 241 bp chlamydial specific product in an ethidium bromide-stained agarose gel. 
tive results (Persing 1993, Verkooyen et al. 1996). Addition of an amplifiable fragment of foreign DNA in the PCR as a hybrid internal control (HIC), is a simple strategy to identify specimens containing inhibitors (Pham et al. 1998). We constructed a HIC, pPC396, which generates a 350 bp final amplification product by nested PCR. The construction was done using a pair of hybrid primers PKL1 (5'CGAGTTACTAAGAGACGCCGTTTGG-3'); PKL2 (5'CCCGGGATTGGTGTTTACGAAGGTT-3') that contain sequences of the KL1 and KL2 primers flanking two primers that target sequences of a $335 \mathrm{bp}$ lambda phage DNA fragment. The same rationale was followed in a second round using an other pair of hybrid primers KL3 (5'CCCACCATTTTTCCGGAGCG-3'); KL4 (5'-GAGCT AAAAAAAATCAATGC-3') to generate an heterologous fragment that was finally amplified by the external primers KL5/KL6 (Fig. 1B). The 396 bp DNA fragment obtained was cloned in a pGEM-T vector (Promega), rendering pPC396. Plasmids containing the hybrid DNA were quantified, diluted and used as HIC by adding them to the first reaction tube of each nested PCR test.

The sensitivity of nested PCR was determined using decreasing quantities of DNA purified from tittered $C$. trachomatis cultures (Fig. 2A). The assay was able to detect DNA corresponding to one EB in the reaction mixture. However, the sensitivity under clinical test conditions could be lower due to PCR inhibitors not completely removed during the DNA purification. To explore this possibility, 10 cervical secretion samples found negative for $C$. trachomatis were pooled and $500 \mu 1$ were spiked with $10^{6} \mathrm{~EB}$ (Pannekoek et al. 2000). Then, tenfold serial dilutions were made using the negative cervical secretion pool and total DNA was purified by treatment with proteinase $\mathrm{K}$ in the presence of detergent, followed by phenol/chloroform extraction and alcoholic precipitation (Maniatis et al. 1982). DNA was resuspended in $50 \mu 1$ of sterile water and $2 \mu \mathrm{l}$ were used in each reaction. The resulting sensitivity in different experimental rounds in spiked samples ranged between 1 to 10 EB DNA per reaction (Fig. 2B shows a typical result).

Although nested PCR is superior both in sensitivity and specificity relative to a single PCR, it is also much more prone to contamination since the product of the first reaction needs to be transferred to a second tube. To avoid this problem a one-tube nested PCR assay was developed. First, we used the four oligonucleotides in a single reaction; however, the high sensitivity of the standard nested PCR was not attained. In a second attempt, a twostep one-tube nested assay was performed. In order to find the best conditions for the whole assay, we tested different concentrations for the components of each reaction, final volumes and numbers of amplification cycles. The results obtained suggested that high concentrations of oligonucleotides and dNTPs in the first reaction interfere with the second reaction leading to lower sensitivities (not shown). Optimal results were obtained with a first PCR in $30 \mu \mathrm{l}$ of final volume, containing lower quantities of dNTPs ( $2.5 \mathrm{nmol}$ each), KL5/KL6 oligonucleotides (6 pmol each) and cycled 25 times, followed by the addition of $50 \mu \mathrm{l}$ of the second reaction mixture and 35 extra cycles. Twenty copies of pPC396 were added to the first reaction mixture. The sensitivity under these conditions was the same as that obtained for the two-tube nested PCR assay (Fig. 2C). Although this method involves the opening of the tubes after the 1st PCR, which can lead to aerosol contamination, in our experience the major source of contamination was the pippeting of PCR product, and we eliminated contaminations with this two-step, one-tube nested PCR. In all the sensitivity experiments, 20 copies of internal control plasmid pPC 396, which yield a $350 \mathrm{bp}$ final product, was added to the first reaction. The amount of internal control added into the reaction tube, was previously optimized in order to generate the expected amplification product without inhibiting the amplification of the chlamydial specific product by competition (data not shown).

Finally, in order to determine if our reaction was suitable as a general assay for determination of $C$. trachomatis, the same experiments using other clinical specimens were performed. The sensitivity test was found to be similar with urine, urethral swabs, nasopharyngeal aspirates, and ocular swabs (not shown). All samples were processed as described earlier. Moreover, the performance was independent of operators, Taq polymerase provider or thermal cyclers used.

In conclusion, we report here a one-tube nested PCR assay for detection of $C$. trachomatis in clinical samples that (i) is highly sensitive, being able to detect less than 10 EB per reaction in different biological samples; (ii) allows the detection of false negative results, by using an internal control of amplification; (iii) is robust enough to deal with the changing conditions found in different clinical laboratories.
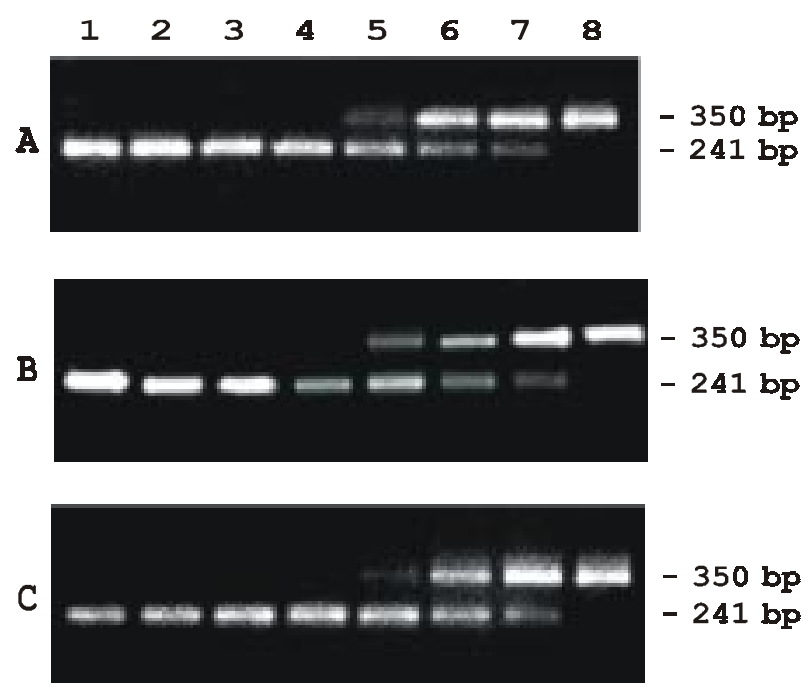

Fig. 2: detection limits of the nested PCR assay. Different lanes correspond to decreasing quantities of chlamydial DNA, from $10^{6}$ EBs in lane 1 to $1 \mathrm{~EB}$ in lane 7 . Lane 8 corresponds to the negative control $(2 \mu 1$ water). In all lanes, 20 copies of pPC396 control plasmid were added to the first reaction tube. A: results of two-tubes nested PCR with DNA from purified EBs; B: two-tubes nested PCR with EBs spiked in cervical fluids; C: one-tube nested PCR with EBs spiked in cervical fluids. DNA from EBs or spiked samples were purified according to standard procedures (Maniatis et al. 1982). 


\section{REFERENCES}

Black C 1997. Current methods of laboratory diagnosis of Chlamydia trachomatis infections. Clin Microbiol Rev 10: 160-184.

Gerbase AC, Rowley JT, Heymann DH, Berkley SF, Piot P 1998. Global prevalence and incidence estimates of selected curable STDs. Sex Transm Infect 74 (Suppl. 1): S12-S166.

Mahony JB, Luinstra KE, Sellors JW, Chernesky MA 1993. Comparison of plasmid and chromosome-based polymerase chain reaction assays for detecting Chlamydia trachomatis nucleic acids. J Clin Microbiol 31: 1753-1758.

Mahony JB, Luinstra KE, Sellors JW, Jang D, Chernesky MA 1992. Confirmatory polymerase chain reaction testing for Chlamydia trachomatis in first-void urine from asymptomatic and symptomatic men. J Clin Microbiol 30: 2241-2245.

Maniatis R, Fritsch EF, Sambrook J 1982. Molecular Cloning: a Laboratory Manual, Cold Spring Harbor Laboratory, Cold Spring Harbor, NY, p. 458-459.

Marrazzo JM, Stamm E 1998. New approaches to the diagnosis, treatment and prevention of chlamydial infection. Curr Top Clin Infect Dis 18: 37-59.

Pannekoek Y, Westenberg SM, de Vries J, Repping S, Spanjaard L, Eijk P, van der Ende A, Dankert J 2000. PCR assessment of Chlamydia trachomatis infection of semen specimens processed for artificial insemination. J Clin Microbiol 38: 3763-3767.

Persing DH 1993. In vitro nucleic acid amplification techniques. In DH Persing, TF Smith, FC Tenover, TJ White (eds), Diagnostic Molecular Microbiology. Principles and Applications, American Society for Microbiology, Washington D.C., p. 51-87.

Pham DG, Madico GE, Quinn TC, Enzler MJ, Smith TF, Gaydos CA 1998. Use of lambda phage DNA as a hybrid internal control in a PCR-enzime immunoassay to detect Chlamydia pneumoniae. J Clin Microbiol 36: 1919- 1922.

Saiki RK, Scharf S, Faloona F, Mullis KB, Horn GT, Erlich HA, Arnheim N 1985. Enzymatic amplification of $\beta$-globin genomic sequences and restriction site analysis for diagnosis of sickle cell anemia. Science 230: 1350-1354.

Schmidt BL 1997. PCR in laboratory diagnosis of human Borrelia burgdorferi infections. Clin Microbiol Rev 10: 185201.

Verkooyen RP, Luijendick A, Huisman WM, Goessens WH, Kluytmans JA, van Rijsoort-Vos JH, Verbrugh HA 1996. Detection of PCR inhibitors in cervical specimens by using the Amplicor Chlamydia trachomatis assay. J Clin Microbiol 34: 3072-3074. 